\title{
e-interview
}

\section{Roger Montenegro}

Roger Montenegro is Professor in Psychiatry at University of Buenos Aires and the current Education Secretary for the World Psychiatric Association. He trained in and currently lives in Buenos Aires. His special interest is psychosocial interventions in psychiatry.

If you were not a psychiatrist, what would you do?

I would be engaged in some other humanistic field such as anthropology or sociology.

What has been the greatest impact of your profession on you personally? A better understanding of human behaviour. Also, the opportunity to contribute towards improving mental health and treating patients to provide them with a better quality of life.

What are your interests outside of work?

Socio-economic, political and cultural issues.

Who was your most influential trainer, and why?

The patients themselves, and their families, as they are a permanent source of motivation to obtain new knowledge and conduct research.

What job gave you the most useful training experience?

Inter-disciplinary teamwork and networking with advocacy groups.

Which book/text has influenced you most?

General Psychopathology by K. Jaspers, and many books by other psychopathologists.

What research publication has had the greatest influence on your work?

Salud Mental, edited by Instituto Mexicano de Psiquiatria.

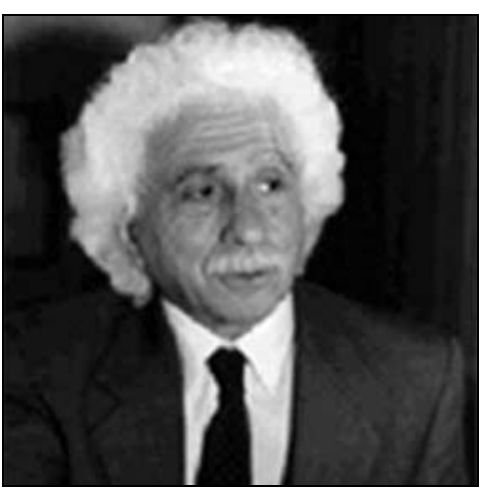

How would you entice more medical students into the profession? By quoting Martin Roth,'Psychiatry is the most human of sciences and the most scientific of humanities'

What is the most important advice you could offer to a new trainee? To behave ethically and with solidarity.

What are the main ethical problems that psychiatrists will face in the future?

Cultural, socio-economic and political conditioning of psychiatric practice, as well as crisis-causing scientific-technological

What part of your work gives you the developments and globalisation.

ost satisfaction?

Teaching.

What do you least enjoy?

Dealing with unethical misbehaviour

of colleagues.

What single change would substantially improve quality of care? A political decision to give high priority to psychiatric services.

What conflict of interest do you encounter most often?

Profit v. public mental health policies.

Do you think psychiatry is brainless or mindless?

Neither brainless nor mindless. There is no brain without mind, and no mind without brain.

What is the most promising opportunity facing the profession? To cure or relieve the suffering of patients, defending their rights and improving their quality of life.

What is the greatest threat?

The intrusion of third parties in the above-mentioned goals.
How would you improve clinical psychiatric training?

By improving knowledge, skills and attitudes.

What single change to mental health legislation would you like to see?

A guarantee to access to mental healthcare for all the population.

How should the role of the Royal College of Psychiatrists change? Increasing its participation in the World Psychiatric Association (WPA)

What is the future for psychotherapy in psychiatry training and practice? Promising.

What single area of psychiatric research should be given priority? Psychosocial research. 